\title{
A Field-Based Study of the Magnitude of Risk Factors and Health Habits in Young Volunteers in the Community
}

Turki Alsafrani ${ }^{1}$, Abdulkarim W. Abukhodair ${ }^{2}$, Osama M. Khojah ${ }^{3}$, Essam I. Jastania ${ }^{3}$, Rawan Alamri ${ }^{4}$, Abdulhalim J. Kinsara 5, 6

1. Orthopaedics, King Saud Bin Abdulaziz University for Health Sciences, College of Medicine-Western Region, Ministry of National Guard Health Affairs, Jeddah, SAU 2. Surgery, King Saud Bin Abdulaziz University for Health Sciences, College of Medicine-Western Region, Ministry of National Guard Health Affairs, Jeddah, SAU 3. Internal Medicine, King Saud Bin Abdulaziz University for Health Sciences, College of Medicine-Western Region, Ministry of National Guard Health Affairs, Jeddah, SAU 4. Cardiac Surgery, King Abdulaziz University Hospital, Jeddah, SAU 5. Cardiology, King Saud Bin Abdulaziz University for Health Sciences, College of Medicine-Western Region, Ministry of National Guard Health Affairs, Jeddah, SAU 6. Cardiology, King Abdullah International Medical Research Center, Jeddah, SAU

Corresponding author: Turki Alsafrani, turkycraft2@gmail.com

\section{Abstract \\ Objective}

A field study is more informative in terms of epidemiological data than a hospital-based study. Undiagnosed risk factors may be discovered in an asymptomatic group. This study aimed to estimate if the community was well informed about the risk factors for coronary artery disease and if that affected the prevalence and the anthropometric among those who participated in the study.

\section{Materials and methods}

A cross-sectional study was conducted, using a consecutive sampling technique. Individuals were interviewed in terms of the risk factors and clinical signs and symptoms. The anthropometric measurements were done on-site to identify asymptomatic risk factors. The survey was utilized to increase the awareness among the participants.

\section{Results}

In total, 193 individuals participated in this study. The mean age of the sample was $36.3 \pm 12.4$ years, with $53 \%$ male. Smoking was the most frequent risk factor (31.6\%), followed by dyslipidemia (22.5\%), hypertension (16.6\%), and diabetes mellitus (14.5\%). Almost half of the sample participated in sports for one to two hours per week (40\%). Almost all consumed fast food at least once a week, and $16.6 \%$ consumed fast food more than four times a week. The average systolic blood pressure was $129.41 \pm 22.5 \mathrm{mmHg}$ and the average body mass index (BMI) $27.6 \pm 7.2 \mathrm{~kg} / \mathrm{m} 2$.

Review began 06/06/2021 Review ended 06/12/2021 Published 06/22/2021

(c) Copyright 2021 Alsafrani et al. This is an open access article distributed under the terms of the Creative Commons Attribution License CC-BY 4.0., which permits unrestricted use, distribution, and reproduction in any medium, provided the original author and source are credited.

\section{Conclusion}

Dyslipidemia was the most prevalent risk factor. Hypertension and diabetes mellitus are on top of the risk factor pyramid in commonality. An early diagnosis is important to decrease the incidence of cardiovascular disease. The consumption of fast food and obesity are relatively high and require educational interventions and more available healthy food. Screening through social media and primary health care centers may avert a negative outcome.

Categories: Cardiology, Family/General Practice, Epidemiology/Public Health

Keywords: cigarette smoking, kingdom of saudi arabia (ksa), hypertension, dyslipidemia, diabetes mellitus, young people, community obesity

\section{Introduction}

The World Health Organization stated that in 2019, mortality due to ischaemic heart disease (IHD) increased by more than 1.2 million in upper-middle-income countries. IHD and stroke were the two major causes of death [1]. Traditional risk factors are still prevalent, underdiagnosed, or under-treated. In Saudi Arabia, a study reported that a high-fat diet was the most prevalent risk factor (73.4\%), followed by physical inactivity (57.9\%). It should be noted that this study was conducted with medical students, a well-educated group [2]. Another study estimated the prevalence of the conventional risk factors, including hypertension (HTN), dyslipidemia, diabetes mellitus (DM), and smoking, in coronary artery disease (CAD) patients as $84.6 \%$ in women and $80 \%$ in men [3]. To reduce the burden of cardiovascular disease, we should determine the risk factors in the community and prevent their progression. An updated and inclusive prevalence study in the 


\section{Cureus}

community measures the risk factors and reduces the knowledge deficit. This article was previously presented as a meeting abstract at the ESC Acute CardioVascular Care 2021 annual scientific meeting on March 13, 2021.

\section{Materials And Methods}

\section{Study setting and participants}

We conducted a cross-sectional study to measure the prevalence of CAD-related risk factors in the community of the Western Region of Saudi Arabia. A non-probability consecutive sampling technique was used. The questionnaire was partly self-administered and completed by a trained data collector. Participants who were 18 years and older were included. Informed consent was obtained.

\section{Study variables}

Demographic information was collected and dichotomous questions were used to explore current chronic diseases, current diagnoses of HTN, DM, dyslipidemia, and chronic heart failure. Questions related to lifestyle risk included hours of activities per week, the type of activities, fast-food meals consumed per week, and smoking. The second section was the measurement of weight, height, systolic and diastolic blood pressure in both arms. The BMI was classified according to WHO classes.

\section{Statistical methods and ethical considerations}

The quantitative variables are presented as mean \pm standard deviation and the qualitative variables as frequency and percentage. The chi-square test or Fisher's exact test, as appropriate, assessed the association between two categorical variables. The statistical analyses were performed with IBM Statistical Software for Social Sciences (SPSS Statistics) for Windows, version 25 (IBM Corp., Armonk, N.Y., USA). Ethical approval was obtained from the Institution Review Board of King Abdullah International Medical Research Center.

\section{Results}

In total, 193 mall visitors volunteered to participate in the study. More than half were male ( $\mathrm{n}=97,53.9 \%$ ), and the mean age was $36.1 \pm 12.4$ years $(95 \% \mathrm{CI}=34.3$ to 38.1 years). Most of the participants were younger than 39 years (62\%), and overweight or obese (65.4\%). The mean systolic blood pressure was $129.41 \pm 22.5$ $\mathrm{mmHg}(95 \% \mathrm{CI}=126.1$ to $132.6 \mathrm{mmHg})($ Table 1$)$.

\begin{tabular}{|c|c|c|c|}
\hline \multicolumn{2}{|l|}{ Demographics } & $\mathbf{n}$ & $\%$ \\
\hline \multirow{2}{*}{ Gender } & Male & 97 & 53.9 \\
\hline & Female & 83 & 46.1 \\
\hline \multirow{4}{*}{ Age (y) } & Below than 29 Years & 58 & 32.4 \\
\hline & $30-39$ years & 53 & 29.6 \\
\hline & $40-49$ years & 37 & 20.7 \\
\hline & Above than 50 years & 31 & 17.3 \\
\hline \multirow{4}{*}{ BMI $\left(\mathrm{kg} / \mathrm{m}^{2}\right)$} & Underweight & 15 & 8.1 \\
\hline & Normal weight & 49 & 26.5 \\
\hline & Overweight & 57 & 30.8 \\
\hline & Obese & 64 & 34.6 \\
\hline Blood pressure $(\mathrm{mmHg})($ mean $\pm \mathrm{SD})$ & \multicolumn{3}{|l|}{$129.4 \pm 22.5 \mathrm{mmHg}$} \\
\hline
\end{tabular}

\section{TABLE 1: Demographic information of the sample}

The highest reported risk factor in the sample was dyslipidemia (22.5\%), followed by HTN (16.6\%), DM (14.5\%), hypothyroidism (4.3\%), and congestive cardiac failure (2.6\%). The majority of the group who had DM were above 50 years old (60\%) and dyslipidemia was diagnosed in $43.9 \%$. The majority of the group (78.6\%) with previously diagnosed HTN were above 40 years old. The highest proportion of the overweight participants were 30-39 years old. There was a significant association between age and comorbidities ( $p$ > 0.001) (Table 2). 


\section{Cureus}

\begin{tabular}{|c|c|c|c|c|c|c|c|}
\hline \multicolumn{2}{|l|}{ Comorbidities } & Below 29 Years (\%) & $30-39$ years $(\%)$ & 40-49 years (\%) & Above 50 years (\%) & Total & $p$-value \\
\hline \multirow{2}{*}{ Diabetes Mellitus } & Yes & 1 (4) & $4(16)$ & $5(20)$ & $15(60)$ & 25 & \multirow{2}{*}{$<0.001^{\star}$} \\
\hline & No & $57(37)$ & $49(31.8)$ & $32(20.8)$ & $16(10.4)$ & 154 & \\
\hline \multirow{2}{*}{ Hypertension } & Yes & $1(3.6)$ & $5(17.9)$ & $10(35.7)$ & $12(42.9)$ & 28 & \multirow{2}{*}{$<0.001$} \\
\hline & No & $57(37.7)$ & $48(31.8)$ & 27 (17.9) & $19(12.6)$ & 151 & \\
\hline \multirow{2}{*}{ Congestive Heart Failure } & Yes & $1(20)$ & $1(20)$ & $1(20)$ & $2(40)$ & 5 & \multirow{2}{*}{$0.598^{\star \star}$} \\
\hline & No & $56(32.4)$ & $52(30.1)$ & $36(20.8)$ & $29(16.8)$ & 173 & \\
\hline \multirow{2}{*}{ Dyslipidemia } & Yes & $1(2.4)$ & $12(29.3)$ & $10(24.4)$ & $18(43.9)$ & 41 & \multirow{2}{*}{$<0.001^{\star}$} \\
\hline & No & $55(41.4)$ & $40(30.1)$ & $26(19.5)$ & $12(9)$ & 133 & \\
\hline \multirow{2}{*}{ Hypothyroidism } & Yes & $1(12.5)$ & $3(37.5)$ & $1(12.5)$ & $3(37.5)$ & 8 & \multirow{2}{*}{$0.290^{\star \star}$} \\
\hline & No & 56 (33.5) & $50(29.9)$ & $35(21)$ & $26(15.6)$ & 167 & \\
\hline \multirow{4}{*}{ Body Mass Index } & Underweight & $12(80)$ & $2(13.3)$ & $1(6.7)$ & $0(0)$ & 15 & \multirow{4}{*}{$<0.001$} \\
\hline & Normal weight & $23(50)$ & $13(28.3)$ & $5(10.9)$ & $5(10.9)$ & 46 & \\
\hline & Overweight & 10 (18.2) & $22(40)$ & $14(25.5)$ & $9(16.4)$ & 55 & \\
\hline & Obese & $10(17.5)$ & $15(26.3)$ & $16(28.1)$ & $16(28.1)$ & 57 & \\
\hline
\end{tabular}

\section{TABLE 2: Association between age groups and comorbidities}

* $=$ chi-square test

${ }^{\star *}=$ Fisher's exact test

A third of the sample smoked (31.6\%), with the majority smoking cigarettes (89.2\%). Fast-food meal consumption was high, with four or more fast-food meals per week (24.6\%) and a third of the sample consumed one meal per week (34.3\%). The fast-food consumption was significantly higher in the younger age group ( $\mathrm{p}=0.037$ ), which was concerning as it was accompanied by physical inactivity. In the younger age group, a third were physically inactivity (28.3\%) and 39.8\% were active one to two hours per week. For the group that exercised, the main activity was walking (64.1\%), though for a short period (Table 3). 


\begin{tabular}{|c|c|c|c|c|c|c|c|}
\hline \multicolumn{2}{|l|}{ Habits } & $\begin{array}{l}\text { Below } 29 \text { Years } \\
\text { (\%) }\end{array}$ & $\begin{array}{l}\text { 30-39 years } \\
(\%)\end{array}$ & $\begin{array}{l}\text { 40-49 years } \\
(\%)\end{array}$ & $\begin{array}{l}\text { Above } 50 \text { years } \\
\text { (\%) }\end{array}$ & Total & $\begin{array}{l}\mathrm{p}- \\
\text { value }\end{array}$ \\
\hline \multirow{2}{*}{ Smoking } & Yes & $20(35.1)$ & $21(36.8)$ & $11(19.3)$ & $5(8.8)$ & 57 & \multirow{2}{*}{$0.149^{*}$} \\
\hline & No & $37(30.6)$ & $32(26.4)$ & $26(21.5)$ & $26(21.6)$ & 121 & \\
\hline \multirow{2}{*}{ Smoking Method } & Cigarettes & $16(31.4)$ & $20(39.2)$ & $10(19.6)$ & $5(9.8)$ & 51 & \multirow{2}{*}{$0.368^{\star \star}$} \\
\hline & E-cigarettes & $4(66.7)$ & $1(16.7)$ & $1(16.7)$ & $0(0)$ & 6 & \\
\hline \multirow{5}{*}{$\begin{array}{l}\text { Fast-Food Meals } \\
\text { Consumption }\end{array}$} & No Meals & $0(0)$ & $1(100)$ & $0(0)$ & $0(0)$ & 1 & \multirow{5}{*}{$0.037^{*}$} \\
\hline & One Meal & $13(22.4)$ & $13(22.4)$ & $16(27.6)$ & $16(27.6)$ & 58 & \\
\hline & Two Meals & $14(40)$ & $11(31.4)$ & $6(17.1)$ & $4(11.4)$ & 35 & \\
\hline & Three Meals & $14(53.8)$ & $8(30.8)$ & $1(3.8)$ & $3(11.5)$ & 26 & \\
\hline & $\begin{array}{l}\text { More Than } 4 \\
\text { Meals }\end{array}$ & $15(35.7)$ & $16(38.1)$ & $7(16.7)$ & $4(9.5)$ & 42 & \\
\hline \multirow{4}{*}{ Hours of Exercise $p$} & No Exercises & $14(30.4)$ & 15 (32.6) & $10(21.7)$ & $7(15.2)$ & 46 & \multirow{4}{*}{$0.442^{\star}$} \\
\hline & 1-2 hours & $23(31.9)$ & $20(27.8)$ & $14(19.4)$ & $15(20.8)$ & 72 & \\
\hline & 3-4 hours & $8(40)$ & $2(10)$ & $4(20)$ & $6(30)$ & 20 & \\
\hline & 5 hours and more & $13(32.5)$ & 15 (37.5) & $9(22.5)$ & $3(7.5)$ & 40 & \\
\hline \multirow{5}{*}{ Type of Exercises } & Walking & $23(27.1)$ & $22(25.9)$ & $20(23.5)$ & $20(23.5)$ & 85 & \multirow{5}{*}{$0.427^{\star}$} \\
\hline & Running & $5(35.7)$ & $4(28.6)$ & $3(21.4)$ & $2(14.3)$ & 14 & \\
\hline & Weightlifting & $7(43.8)$ & $6(37.5)$ & $3(18.8)$ & $0(0)$ & 16 & \\
\hline & Swimming & 6 (46.2) & $1(7.7)$ & $4(30.8)$ & $2(15.4)$ & 13 & \\
\hline & Others & (50) & $2(33.3)$ & $1(16.7)$ & $0(0)$ & 6 & \\
\hline
\end{tabular}

\section{TABLE 3: Association between age groups and lifestyle habits}

\section{$*$ chi-square test \\ ${ }^{* *}=$ Fisher's exact test}

\section{Discussion}

Diabetes mellitus, HTN, and dyslipidemia were more prevalent in the older age groups. Although the study highlights a high rate of risk factors, the prevalence of the risk factors is lower than reported in previous studies. In the current study, dyslipidemia was $22.5 \%$, compared to $45 \%$ reported in 2007 [4]. HTN prevalence was $16.6 \%$ compared to $26.1 \%$ in 2000 [5], and DM $14.5 \%$ compared to $23.7 \%$ in 2004 [6]. However, the prevalence of DM, HTN, and dyslipidemia in the population is high compared with other global populations [7].

The mean blood pressure is higher than recommended in current guidelines [8]. The mean blood pressure and BMI also increased [9]. Increased awareness of physical activity was noted but the hours of physical activity were less than the recommended guideline [10]. In 2007, the prevalence of inactivity was $96.1 \%$ compared with $28.3 \%$ in the current study [11]. The challenge related to physical inactivity is global, with a higher prevalence reported in both developing and developed countries [12-14].

The consumption of fast food in the younger age group is alarming and much higher compared to other populations $[14,15]$. The efficient use of social media and the mandatory display of the calories of different food items may support a lifestyle change.

The younger age groups had a higher proportion of cigarette smokers, slightly better than reported in a small study in 2003, which was 52.3\% [16]. The decline in smoking in developing countries is not comparable to many developed countries and smoking cessation requires more attention [17]. 
Based on the results, more age-targeted preventive measures such as educational programs for weight loss, the nutritional values of fast-food meals, programs for smoking cessation, and screening programs for dyslipidemia and HTN are required. The research findings increase the growing body of knowledge about the risk factors in the community and the understanding of the most effective preventive strategies.

The limitations of the study were the cross-sectional design, which may lead to bias, as well as the low sample size. The COVID-19 social distancing limited the expansion. However, a field study is known to require extra effort, manpower, and funding, which were not available for our study.

\section{Conclusions}

Dyslipidemia was the most prevalent risk factor, followed by hypertension. Unhealthy lifestyle habits, including smoking, and the high consumption of fast-food meals are prevalent in the younger age groups, resulting in higher blood pressure and BMI than recommended in the current guidelines. Although the sample was among young patients, the gap in awareness of risk factors and itemized components of metabolic syndrome was prevalent. We recommend a focused approach to diet and exercise at an early age and beginning at early school. More effort to provide a suitable environment and the use of social media will enhance the success of this approach. Attention to an early screening of metabolic elements is an essential additional component to reduce the risk of cardiovascular disease.

\section{Additional Information \\ Disclosures}

Human subjects: Consent was obtained or waived by all participants in this study. King Abdullah International Medical Research Center issued approval SP19/411/J. Ethical approval was obtained from the Institution Review Board of King Abdullah International Medical Research Center. Animal subjects: All authors have confirmed that this study did not involve animal subjects or tissue. Conflicts of interest: In compliance with the ICMJE uniform disclosure form, all authors declare the following: Payment/services info: All authors have declared that no financial support was received from any organization for the submitted work. Financial relationships: All authors have declared that they have no financial relationships at present or within the previous three years with any organizations that might have an interest in the submitted work. Other relationships: All authors have declared that there are no other relationships or activities that could appear to have influenced the submitted work.

\section{Acknowledgements}

We thank Dr. Mohammed Anwar Khan for his assistance in the statistical analysis and Dr. Mohammed Idriss for his contribution to the design.

\section{References}

1. WHO. Noncommunicable diseases country profiles 2018. (2018). Accessed: June 22, 2021: https://www.who.int/publications/i/item/ncd-country-profiles-2018.

2. Ibrahim NK, Mahnashi M, Al-Dhaheri A, et al.: Risk factors of coronary heart disease among medical students in King Abdulaziz University, Jeddah, Saudi Arabia. BMC Public Health. 2014, 14:411. 10.1186/1471-2458-14-411

3. Khot UN, Khot MB, Bajzer CT, et al.: Prevalence of conventional risk factors in patients with coronary heart disease. JAMA. 2003, 290:898-904. 10.1001/jama.290.7.898

4. Al-Nozha MM, Arafah MR, Al-Maatouq MA, et al.: Hyperlipidemia in Saudi Arabia. Saudi Med J. 2008, 29:282-7.

5. Al-Nozha MM, Abdullah M, Arafah MR, et al.: Hypertension in Saudi Arabia. Saudi Med J. 2007, 28:77-84.

6. Al-Nozha MM, Al-Maatouq MA, Al-Mazrou YY, et al.: Diabetes mellitus in Saudi Arabia . Saudi Med J. 2004, 25:1603-10.

7. Liu R, So L, Mohan S, Khan N, King K, Quan H: Cardiovascular risk factors in ethnic populations within Canada: results from national cross-sectional surveys. Open Med. 2010, 4:e143-53.

8. Bonner L: New AHA/ACC guidelines redefine high blood pressure as 130/80 mm Hg . Blood Pressure. 2018, 24:21-3

9. Movahed MR, Lee JZ, Lim WY, Hashemzadeh M, Hashemzadeh M: Strong independent association between obesity and essential hypertension. Clin Obes. 2016, 6:189-92. 10.1111/cob.12139

10. Piercy KL, Troiano RP, Ballard RM, et al.: The Physical Activity Guidelines for Americans . JAMA. 2018, 320:2020-8. 10.1001/jama.2018.14854

11. Al-Nozha MM, Al-Hazzaa HM, Arafah MR, et al.: Prevalence of physical activity and inactivity among Saudis aged 30-70 years. A population-based cross-sectional study. Saudi Med J. 2007, 28:559-68.

12. Fakhrzadeh H, Djalalinia S, Mirarefin M, et al.: Prevalence of physical inactivity in Iran: a systematic review . J Cardiovasc Thorac Res. 2016, 8:92-7. 10.15171/jcvtr.2016.20

13. Souza AM, Fillenbaum GG, Blay SL: Prevalence and correlates of physical inactivity among older adults in Rio Grande do Sul, Brazil. PLoS One. 2015, 10:e0117060. 10.1371/journal.pone.0117060

14. Pieroni L, Salmasi L: Fast-food consumption and body weight. Evidence from the UK. Food Policy. 2014, 46:94-105. 10.1016/j.foodpol.2014.02.004

15. Paeratakul S, Ferdinand DP, Champagne CM, Ryan DH, Bray GA: Fast-food consumption among US adults and children: dietary and nutrient intake profile. J Am Dietetic Assoc. 2003, 103:1332-8. 10.1016/S0002- 


\section{Cureus}

8223(03)01086-1

16. Al-Haddad NS, Al-Habeeb TA, Abdelgadir MH, Al-Ghamdy YS, Qureshi NA: Smoking patterns among primary health care attendees, Al-Qassim region, Saudi Arabia. East Mediterr Health J. 2003, 9:911-22.

17. Janssen F, El Gewily S, Bardoutsos A: Smoking epidemic in Europe in the 21st century . Tob Control. 2020, 10.1136/tobaccocontrol-2020-055658 